\title{
ESTRUTURA E COMPOSIÇÃO FLORÍSTICA DE UM CAMBARAZAL NO PANTANAL DE POCONÉ-MT.'
}

\author{
Marcelo Trindade Nascimento ${ }^{2}$ \\ Cátia Nunes da Cunha ${ }^{3}$
}

Recebido em 3-3-88. Aceito em 17-8-88.

RESUMO - (Estrutura e composição florística de um cambarazal no pantanal de Poconé, MT). Neste trabalho foi estudado um cambarazal localizado no pantanal de Poconé, $\mathrm{km} 94$ da Rodovia Transpantaneira. Um total de $1.500 \mathrm{~m}^{2}$ de área foram amostrados e divididos em três transecções de 10 × $50 \mathrm{~m}$. Todas as plantas com circunferência à altura o solo $\geqslant 10 \mathrm{~cm}$ foram mapeadas e medidas para a obtenção dos parâmetros estruturais de densidade relativa, freqüência absoluta e relativa, dominância relativa e índice de valor de importância. Foi amostrado um total de 631 indivíduos, distribuídos entre 15 famílias, 19 gêneros e 23 espécies. Vochysia divergens foi a espécie que apresentou o maior IVI, seguida de Erythroxylum sp. e Aulomyrcia mutabilis. A riqueza florística do cambarazal estudado foi menor que a de áreas de mata amazônica de terra firme, mata atlântica e mata de igapó, sendo sereelhante à da caatinga amazônica. Neste trabalho discutiu-se a hipótese de $\boldsymbol{V}$. divergens ser uma espécie colonizadora de campos inundáveis no pantanal de Poconé e as fases de ocupação e formação de um cambarazal.

Palavras-chave: cambarazal, estrutura, florística, pantanal.

ABSTRACT - (Structure and floristic composition of a "cambarazal" in the "pantanal" of Poconé, Mato Grosso, Brazil.) A study was made of a "cambarazal" located in the municipality of Poconé, State of Mato Grosso, $\mathrm{km} 94$ of the Transpantaneira Road. An area of $1.500 \mathrm{~m}^{2}$ was sampled and divided in three transects of $10 \times 50 \mathrm{~m}$. All trees with circumference at soil level $\geqq 10 \mathrm{~cm}$ were measured to obtain data on relative density, absolute and relative frequency, relative dominance and importance value. A total of 15 families, 19 genera and 23 species were found. Vochysia divergens was considered to be the most important species followed by Erythroxylum sp.

1 - Parte deste trabalho foi apresentado no $37^{\circ}$ Congresso Nacional de Botânica, Ouro Preto (MG), de 19 a 26 de janeiro de 1986.

2- Herbário Central, UFMT, 78096, Cuiabá-MT.

3 - Departamento de Ciências Biológicas UFMT, 78096, Cuiabá-MT. 
and Aulomyrcia mutabilis. The floristic richness of the "cambarazal" was lower than Amazonian rain forest and Atlantic rain forest but similar to "caatinga" woodland. The supposition that $V$. divergens is a colonist species of marshes in the Poconé "pantanal" and the phases of the process of occupation and formation of a "cantrarazal" were discussed.

Key words: "cambarazal", structure, floristics, "pantanal" (Brazil).

\section{Introdução}

O pantanal mato-grossense ocupa uma área de $139.111 \mathrm{~km}^{2}$ do território brasileiro (Adamoli, 1982) e está localizado na bacia do alto Rio Paraguai. Segundo Rizzini (1979), o pantanal é formado por um mosaico de comunidades hidrófilas submersas e natantes, helófilas, mesófilas e até xerófilas. Apresenta também tipos vegetacionais com predominância de uma única espécie arbórea, como a cambarazal, carandazal, paratudal e outros.

O termo cambarazal é utilizado para definir um tipo vegetacional formado basicamente por indivíduos de Vochysia divergens Pohl, Vochysiaceae, conhecida popularmente por cambará (Fig. 1).

A ocorrência de $V$. divergens está relacionada principalmente com áreas periodicamente inundáveis (Stafleu, 1948; Prance \& Schaller, 1982), sendo encontrada com freqüência no pantanal mato-grossense, formando o cambarazal em campo inundável ou ocorrendo como indivíduos isolados na mata ciliar. No Estado de Mato Grosso sua maior incidência está nos pantanais dos municípios de Poconé, Cáceres, Barão de Melgaço e Santo Antônio do Leverger (Nascimento \& José, 1986).

$\mathrm{Na}$ literatura científica são poucos os trabalhos relacionados com cambarazal, sendo em sua maioria descrições breves e/ou resumidas ou apenas citações (Veloso, 1947 e 1972; Almeida \& Lima, 1959; Prance \& Schaller, 1982; Projeto Radambrasil, 1982). Os trabalhos citando a existência de outros tipos vegetacionais homogêneos no pantanal são em maior número, podendo ser destacados os de Hoehne (1923, 1936), Kuhlmann (1953, 1954), Rizzini (1979), Adamoli (1982), além dos já citados anteriormente.

O objetivo deste trabalho foi estudar a composição florística, a diversidade de espécies arbóreas e alguns aspectos da estrutura de um cambarazal como: distribuição das classes de circunferência à altura do solo e do peito, densidade absoluta e relativa e índice de valor de importância das espécies lenhosas presentes.

\section{Material e métodos}

A) Área de estudo

O pantanal de Poconé, situado ao sul da cidade de Poconé, está balizado a 
norte pela depressão do Rio Paraguai, a leste e a sul pelo pantanal de Paiaguás e a oeste pela província serrana (Projeto Radambrasil, 1982). Os solos que predominam no pantanal de Poconé apresentam uma textura de média a argilosa e são dos tipos planossolos solódicos, lateritas hidromórficas solódicas e hidromórfico cinzento. A vegetação é composta por campos inundáveis, matas ciliares, formações florestais e arbustivas e praticamente não ocorrem as formas pertencentes à província fitogeográfica dos cerrados. Quando estas formas ocorrem, estão distribuídas quase que exclusivamente na periferia deste pantanal (Adamoli, 1982).

O cambarazal estudado está localizado próximo ao km 94 da Rodovia Transpantaneira, na margem direita de quem vai de Poconé para Porto Jofre, na Fazenda Uval (Fig. 2). Esse cambarazal apresenta uma área total de aproximadamente quatro hectares e não foram observados vestígios de corte ou fogo no período do levantamento (nov./85 a mar./86). A ocorrência de gado na área pode ser considerada freqüente.

B) Amostragem

Para a análise da estrutura e composição florística foram amostrados $1.500 \mathrm{~m}^{2}$ de área divididas em três transecções de $500 \mathrm{~m}^{2}(10 \mathrm{~m} \times 50 \mathrm{~m})$, que foram subdivididas em parcelas de $100 \mathrm{~m}^{2}(10 \mathrm{~m} \times 10 \mathrm{~m})$. A localização das transecções foi baseada na fitofisionomia do cambarazal e o parâmetro utilizado para a divisão foi a altura de suas árvores, estimada por observação visual e posterior medição. Um perfil $(1 \mathrm{~m} \times 30 \mathrm{~m})$ da distribuição das árvores com circunferência à altura do solo (CAS) maior ou igual a $10 \mathrm{~cm}$ foi realizado em cada transecção. O local da primeira transecção era nitidamente formado por indivíduos mais baixos que os da segunda transecção, que por sua vez eram mais baixos que os da terceira (Fig. 3). Todos os indivíduos arbustivos-arbóreos com CAS $\geqslant 10 \mathrm{~cm}$ foram medidos e mapeados. Os indivíduos de $V$. divergens menores que $10 \mathrm{~cm}$ de CAS e maiores que $20 \mathrm{~cm}$ de altura foram contados mas não mapeados. $\mathrm{O}$ material botânico em estado reprodutivo foi coletado, herborizado e incorporado ao acervo do Herbário Central da Universidade Federal de Mato Grosso, Cuiabá.

A altura da lâmina d'água em relação ao solo para cada transecção foi estimada com base em medições das marcas d'água nos troncos de algumas árvores dentro das transecções e de alguns indivíduos isolados no campo.

C) Análise dos dados

$\mathrm{Na}$ análise da estrutura do cambarazal foram utilizados os parâmetros de freqüência absoluta ( $\mathrm{Fa}$ ) e relativa (FR), densidade absoluta (DA) e relativa (DR), dominância relativa (DoR) e índice de valor de importância (IVI) (Curtis \& McIntosh, 1950), que são expressos, respectivamente, por:

$\mathrm{Fa}=100 \mathrm{nqi} / \mathrm{nQ} ; \mathrm{FR}=100(\mathrm{Fa} / \mathrm{FA}) ; \mathrm{DA}=\mathrm{ni} / \mathrm{A} ; \mathrm{DR}=100 \mathrm{ni} / \mathrm{N} ; \mathrm{DoR}=$ $100(\mathrm{ABi} / \mathrm{AB})$ e IVI $=\mathrm{FR}+\mathrm{DR}+\mathrm{DoR}$.

Onde:

nqi $=$ número de quadrados em que a espécie i ocorre; 
$\mathrm{nQ}=$ número de quadrados examinados $(10 \mathrm{~m} \times 10 \mathrm{~m})$;

$\mathrm{N}=$ número total de indivíduos amostrados na área, independentes da espécie a que pertençam;

$\mathrm{ni}=$ número de indivíduos amostrados da espécie $\mathrm{i}$;

$\mathrm{A}=$ área amostrada;

$\mathrm{ABi}=$ área basal específica total;

$\mathrm{AB}=$ área basal de todas as espécies;

$\mathrm{Fa}=$ freqüência absoluta específica;

$\mathrm{FA}=$ soma das freqüências absolutas de todas as espécies amostradas.

A diversidade de espécies calculada com base no índice de diversidade e eqüitabilidade, segundo a fórmula de Shannon-Wiener (Krebs, 1976, pp. 506-7), foi utilizada para a análise de heterogeneidade florística. Os índices de diversidade $\left(H^{\prime}\right)$, diversidade máxima (H'máx) e uniformidade ou eqüitabilidade estão representados, respectivamente pelas expressões:

$H^{\prime}=\Sigma$ pi $\log _{2}$ pi; H' máx $=\log _{2} \mathrm{~S} ; \mathrm{E}=\mathrm{H}^{\prime} / \mathrm{H}^{\prime}$ máx.

Onde:

$\mathrm{S}=$ número de espécies;

pi $=$ proporção dos indivíduos de uma espécie na comunidade (ni/N).

\section{Resultados}

Um total de 631 indivíduos foi amostrado. Estes indivíduos estão distribuídos entre 15 famílias, 19 gêneros e 23 espécies (Tabela 1).

As famílias com as maiores percentagens de indivíduos amostrados foram Vochysiaceae $(74,8 \%)$ Erythroxylaceae (12\%) e Myrtaceae (5,1\%). As 11 famílias e uma indeterminada restante totalizaram $8,5 \%$ do número total dos indivíduos amostrados (Fig. 4).

A família Rubiaceae foi a que apresentou a maior percentagem $(17,4 \%)$ do número de espécies encontrado, seguida de Leguminosae e Myrtaceae, ambas com 13\%. A família Vochysiaceae apresentou uma percentagem de apenas $4,3 \%$, ou seja, ocorreu uma única espécie. As nove famílias e uma indeterminada restante participaram com uma única espécie cada uma e reunidas totalizaram $43,5 \%$ do número de espécies encontrado. Cinco famílias somaram 56,5\% do número de espécies amostrado, sendo a maior diferença $(4,4 \%)$ dentro dessa percentagem entre as famílias Rubiaceae com quatro espécies e Leguminosae com três (Fig. 5).

A maior percentagem da dominância relativa (DoR) por família foi da família Vochysiaceae com 76,5\%, seguida de Myrtaceae com 8,3\%. Sete famílias totalizaram $97,4 \%$ da dominância relativa e dentro dessa percentagem a maior diferença ficou entre Vochysiaceae e Myrtaceae com 68,1\% (Fig. 6).

O índice de valor de importância (IVI) para a família Vochysiaceae foi de 174,3, o mais alto encontrado. A distribuição do IVI para as famílias está representada na Fig. 7. 
As Tabelas 2 e 3 apresentam os dados de IVI, freqüência relativa, densidade relativa, CAS e altura (A) das espécies em cada uma das transecções. $\mathrm{Na}$ transecção 1 só ocorreu $\mathrm{V}$. divergens e, por isso, com valor máximo de IVI (300). Os dados das Tabelas 2 e 3 indicam um aumento na ocorrência de Erythroxylum sp. e Aulomyrcia mutabilis da transecção 2 para a 3. Na transecção 2 V. divergens apresentou um elevado valor de IVI de 193,3, seguida de Erythoxylum sp. com 31,3 e Inga affinis com 21,7. Na transecção 3 o maior IVI encontrado foi de 80,1, tambêm de V. divergens, seguido de Erythroxylum sp. $(58,9)$ e Aulomyrcia mutabilis $(45,7)$.

$\mathrm{O}$ número de indivíduos jovens de $\mathrm{V}$. divergens amostrados nas transecções 1, 2 e 3 foi, respectivamente, 295, 415 e 97, totalizando 807 indivíduos jovens nos $1.500 \mathrm{~m}^{2}$ de área amostrada. $\mathrm{Na}$ transecção 1 , entretanto, foi observado um maior número de indivíduos jovens menores que $20 \mathrm{~cm}$ de altura que nas demais transecções.

$\mathrm{O}$ valor da densidade total por hectare foi de 4.206 árvores com CAS $\geqslant$ $10 \mathrm{~cm}$ e 420 árvores com DAP $\geqslant 10 \mathrm{~cm}$.

As curvas do número de espécie/área (Fig. 8) indicam que para a transecção 2 o número de quadrados amostrados foi insuficiente, podendo ser uma das fases de transição do processo de sucessão que ocorre no cambarazal.

Os índices de diversidade de espécies (H'), diversidade máxima (H'máx) e eqüitabilidade (E) calculados para o cambarazal como um todo foram, respectivamente, $1,56,4,52$ e 0,34 . Na transecção 1 não ocorreu diversidade de espécies e nas transecções 2 e 3 os valores foram, respectivamente, 1,06, 3,32 e 0,32 , e 3,09, 4,39 e 0,7.

A altura da lâmina d'agua acima da superfície do solo foi de $60 \mathrm{~cm}$ no centro da transecção $1 ; 50 \mathrm{~cm}$ no centro da transecção 2 e $45 \mathrm{~cm}$ no centro da transecção 3. No campo a altura média da lâmina d'água foi de $75 \mathrm{~cm}$.

\section{Discussão}

A família Vochysiaceae, na amostragem total, foi a que apresentou a maior percentagem de indivíduos, o maior valor de importância e a menor percentagem de números de espécies, sendo representada apenas por Vochysia divergens. Esta espécie apresentou um alto IVI, e, segundo Goodland (1979), um valor elevado do IVI indica um potencial de predominância desta espécie sobre as demais, ou sua melhor capacidade de tirar proveito do ambiente.

$\mathrm{O}$ maior IVI encontrado na transecção 3 foi V. divergens, que participou com apenas 19 indivíduos, mas alguns com fustes de grossos calibres, o que lhe assegurou um alto valor de dominância relativa, seguida de Erythroxylum sp., que participou com 54 indivíduos, e Aulomyrcia mutabilis com 20 indivíduos. Este fato vem demonstrar que nem sempre um grande número de indivíduos de uma mesma espécie está relacionado com um maior valor de IVI. 
Os dados da estrutura do cambarazal, quando comparados com os de outros tipos vegetacionais, indicam que este é inferior em altura do dossel e DAP máximo se comparado à mata amazônica de terra firme e à mata atlântica, sendo semelhante ao manguezal, à mata de igapó e à campina amazônica (Tabela 4).

A ocorrência de gado, embora freqüente na área, parece não estar afetando a regeneração das espécies arbóreas no cambarazal, principalmente a de $\mathrm{V}$. divergens, que, como já demonstrado anteriormente, ocorre com elevado número de indivíduos jovens.

O cambarazal apresenta uma densidade arbórea semelhante à da mata amazônica de terra firme e à da mata de igapó, sendo inferior ao manguezal e à mata atlântica (Tabela 4). A grande diferença encontrada entre a densidade total do cambarazal, considerando-se as árvores com CAS $\geqslant 10 \mathrm{~cm}(4.206$ ind./ha), e a densidade total de árvores com DAP $\geqslant 10 \mathrm{~cm}$ (420 ind./ha) demonstra que a estrutura do cambarazal é composta de indivíduos de fustes finos.

A diversidade de espécies arbóreas do cambarazal apresentou um valor mais baixo que os encontrados para áreas de mata atlântica, mata amazônica de terra firme e mata de igapó (Tabela 4). A baixa diversidade de espécies arbóreas do cambarazal está relacionada, possivelmente, com a saturação hídrica do solo na época da cheia, podendo ser a água um fator limitante ao estabelecimento das espécies vegetais. Segundo José (1986), o solo do cambarazal apresenta teores de nutrientes semelhantes aos solos de outros tipos de vegetação tropical e conclui que ele é propício ao estabelecimento de inúmeras espécies vegetais, não devendo ser os teores de nutrientes no solo um fator limitante, e sim a saturação hídrica do solo na época da cheia.

No cambarazal, os índices de diversidade de espécies para as transecções são inversamente proporcionais aos valores da altura da lâmina d'água na época da cheia. Keel e Prance (1979) verificaram que na mata de igapó a diversidade de espécies é menor também na parte que sofre maior inundação.

A estrutura e a baixa riqueza de espécies arbóreas do cambarazal são semelhantes às de outros tipos vegetacionais que sofrem influência de fatores ambientais extremos, como o manguezal (Pool et al., 1977) e a caatinga amazônica (Anderson, 1981); entretanto, a mata de igapo, que, como o cambarazal, sofre inundações periódicas, apresenta uma riqueza de espécies arbóreas muito superior à encontrada para o cambarazal (Tabela 4).

Vochysia divergens é uma espécie colonizadora de campos naturais inundáveis no pantanal de Poconé. O cambarazal estudado é jovem e, segundo informações do proprietário da fazenda, possui aproximadamente 20 anos. Seu processo de formação e ocupação, provavelmente, teve início com o estabelecimento e germinação de sementes de indivíduos de $\mathrm{V}$. divergens localizados em matas ciliares próximas, que foram dispersas pelo vento ou talvez pela água na época da cheia (nov./mar.), já que o período de frutificação de V. divergens vai de agosto a novembro. A semente desta espécie parece necessitar de local 
bem iluminado para germinar e suas plântulas devem possuir resistência à carência de oxigênio e luz no período em que se encontram submersas, porém estudos da ecofisiologia das sementes e plântulas são necessários para elucidar esta suposição. Coutinho e Struffaldi (1971) verificaram a ocorrência deste tipo de resistência em plântulas de Parkia auriculata na mata de igapó do Rio $\mathrm{Ne}$ gro.

Segundo o Projeto Radambrasil (1982), V. divergens era originalmente da floresta ciliar dos altos rios Cuiabá e São Lourenço e disseminou-se gradativamente através desses rios sobre as baías já completamente colmatadas, formando adensamentos de tamanho e forma variáveis intercalados na paisagem de savana dessas áreas interfluviais.

$\mathrm{O}$ surgimento de um murundu ou um aumento na declividade do solo favorece o estabelecimento de $\mathrm{V}$. divergens e de outras espécies vegetais que encontram ali melhores condições para se fixarem, por ser um pedaço de solo que pode não sofrer ou permanecer inundado por menos tempo (Fig. 9). Os murundus podem ser de origens diversas, por exemplo, de insetos, como cupins (Veloso, 1972). Segundo Araújo Neto et al. (1986), em áreas de cerrado, os murundus favorecem a colonização por plantas de cerrado e de termiteiro, e sua origem parece estar mais relacionada com a drenagem e erosão diferencial do que com as atividades das térmitas.

$O$ processo de formação de um cambarazal parece ser contínuo e, enquanto no seu centro (ex.: transecção 3) ocorre um declínio na regeneração de $\mathrm{V}$. divergens, na margem há um aumento populacional desta espécie (ex.: transecção 1), ocorrendo deste modo um contínuo avanço do cambarazal sobre os campos inundáveis no pantanal de Poconé (Fig. 1). O centro do cambarazal parece evoluir para uma formação de mata semidecídua, caso as condições favoráveis ao processo sucessório continuem a atuar.

\section{Agradecimentos}

Agradecemos ao Departamento de Ciências Biológicas da UFMT pelas facilidades durante a realização deste trabalho e aos Drs. John D. Hay e Nagib Saddi pelas críticas ao manuscrito. Gostaríamos, também, de agradecer ao $\mathrm{Sr}$. Gonçalo Gomes de Arruda, proprietário da Fazenda Uval, por ter permitido a realização deste trabalho em sua propriedade e aos revisores pelas valiosas criticas.

\section{Referências Bibliograficas}

ADAMOLI, J. 1982. O pantanal e suas relaçōes fitogeográficas com os cerrados. Discussão sobre o conceito de "complexo do pantanal". Anais do XXXII Cong. Nac. de Botânica. Teresina-PI, pp. 109-119. 
ALMEIDA, F.F.M. de \& LIMA, M.A. de. 1959. Planalto Centro-Ocidental e o pantanal mato-grossense. Conselho Nacional de Geografia, Rio de Janerio, 169 pp.

ANDERSON, A.B. 1981. White-sand vegetation of Brasilian Amazonia. Biotropica 13(3): $199-210$.

ARAÚJO NETO, M.D. de, FURLEY, P.A., HARIDASAN, M.\& JOHNSON, C.E. 1986. The murunduns of the cerrado region of Central Brazil. Journal of Tropical Ecology, 2: 17-35.

BLACK, G.A., DOBZANSKY, TH. \& PAVAN, C. 1950. Some attempts to estimate species diversity and population density of trees in Amazonia forest. The Botanical Gazette, 111(4): 413-425.

COUTINHO, L.M. \& STRUFFALDI, Y. 1971. Observações sobre a germinação das sementes e o crescimento das plântulas de uma leguminosae da mata amazônica de igapó (Parkia auriculata Spr.) Phyton, 28(2): 149-159.

CURTIS, J.T. \& McINTOSH, R.P. 1950. The interrelations of certain analytic and synthetic phytosociological characters. Ecology 31: 434-455.

GODLAND, R. 1979. Análise ecológica da vegetação do cerrado. In: GOODLAND, R. \& FERRI, M.G. Ecologia do cerrado. Belo Horizonte, Editora Itatiaia/São Paulo, EDUSP.

HOEHNE, F.C. 1923. Phytophysionomia do cerrado de Matto Grosso. São Paulo, Companhia Melhoramentos, pp. 53-8.

HOEHNE, F.C. 1936. O grande pantanal de Matto Grosso. Bol. Agricultura, São Paulo, série $37 \mathrm{a}:$ 443-470.

JOSÉ, D.M.V. 1986. Aspecto da dinâmica de nutrientes em Vochysia divergens Pohl no pantanal de Poconé. Monografia de especialização em Biologia de Ambientes Inundáveis. UFMT. Cuiabá-MT. 54 pp.

KEEL, S.H.K. \& PRANCE, G.T. 1979. Studies of the vegetation of a white-sand blackwater igapó (rio Negro, Brazil). Acta Amazonica 9(4): 645-655.

KREBS, C.J. 1976. Ecology. The experimental analysis of distribution and abundance. New York, Harper and Row Publisher Inc., 649 pp.

KUHLMANN, E. 1953. Os grandes traços da fitogeografia do Brasil. Bol. Geográfico, 11(117): 618-628.

KUHLMANN, E. 1954. A vegetação de Mato Grosso. Seus reflexos na economia do estado. Revta. Bras. Geogr., 16(1): 77-122.

NASCIMENTO, M.T. \& JOSÉ, D.M.V. 1986. O cambarazal no pantanal de Mato Grosso. Boletim FBCN, 21: 116-123.

POOL, D.J., SNEDAKER, S.C. \& LUGO, A.E. 1977. Structure of mangrove forest in Florida, Puerto Rico, Mexico and Costa Rica. Biotropica, 9(3): 95-212.

PRANCE, G.T. \& SCHALLER, G.B. 1982. Preliminary study of some vegetation types of the pantanal. Mato Grosso, Brazil. Brittonia, 34(2): 228-251.

PROJETO RADAMBRASIL (Ministério das Minas e Energia). 1982. Levantamento de recursos naturais. Rio de Janeiro, vol. 27, 452 pp.

RIZZINI, C.T. 1979. Tratado de fitogeografia do Brasil. Aspectos sociológicos e floristicos. HUCITEC, São Paulo, vol. 2, 374 pp.

SILVA, A.F. \& LEITÃO-FILHO, H.F. 1982. Composição florística e estrutura de um trecho de mata atlântica de encosta no município de Ubatuba (São Paulo, Brasil). Revta. Brasil. Bot., 5: 43-52. 
STAFLEU, F.A. 1948. A monograph of the Vochysiaceae. I. Salvertia and Vochysia. Mede. Bot. Mus. Herb. Rijks Univ., 95: 398-540.

TAKEUCHI, M. 1960a. A estrutura da vegetação na Amazônia. I. A mata pluvial tropical. Bol. Mus. Paraense E. Goeldi, Bot. 6: 1-17.

TAKEUCHI, M. 1960b. A estrutura da vegetação na Amazônia. III. A mata da campina na regiâo do rio Negro. Ibidem, 8: 1-13.

VELOSO, H.P. 1947. Considerações gerais sobre a vegetação do Estado de Mato Grosso. II. Notas preliminares sobre o pantanal e zonas de transição. Mem. Inst. Oswaldo Cruz. 45(1): 253-272.

VELOSO, H.P. 1972. Aspectos fitoecológicos da bacia do alto rio Paraguai. Biogeográfi$c a$, São Paulo, (7): 1-31. 


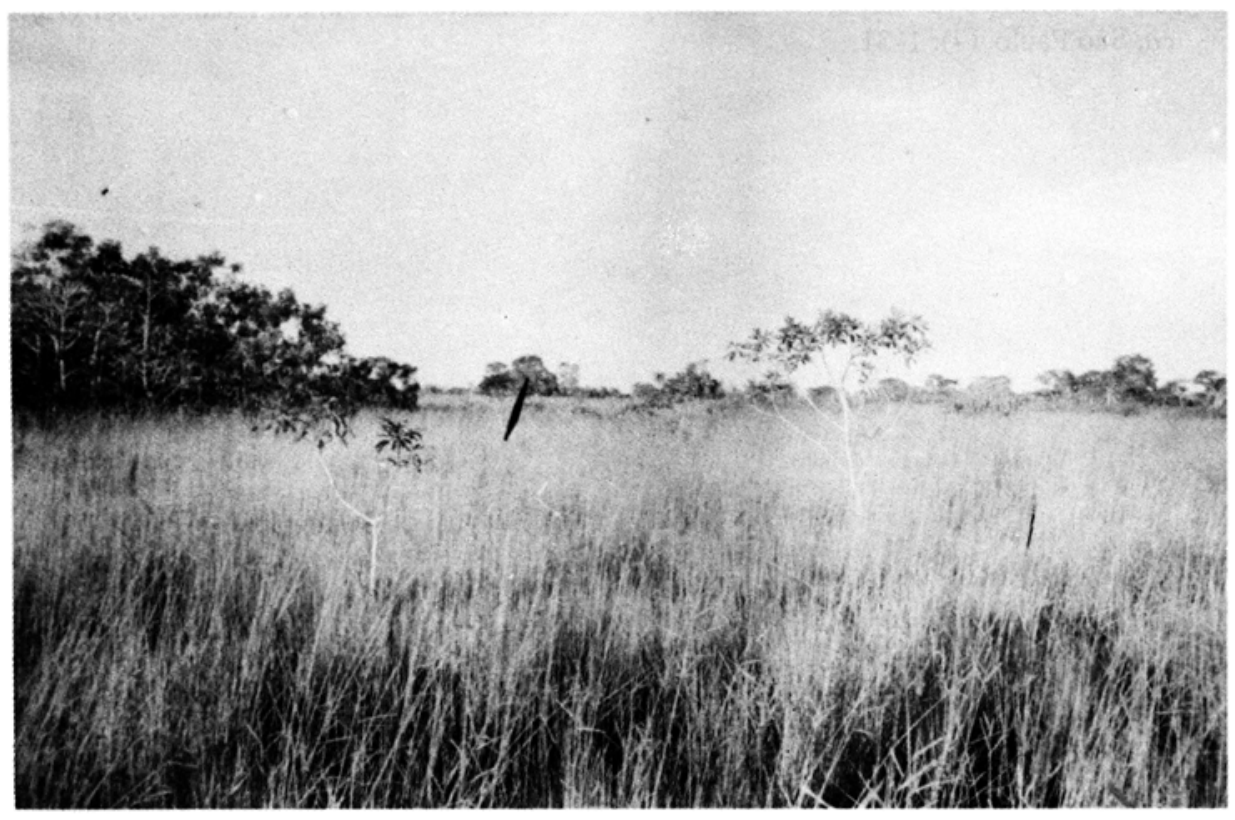

Figura 1 - Vista parcial de um cambarazal (fundo) e indivíduos jovens de Vochysia divergens distantes de sua margem. 


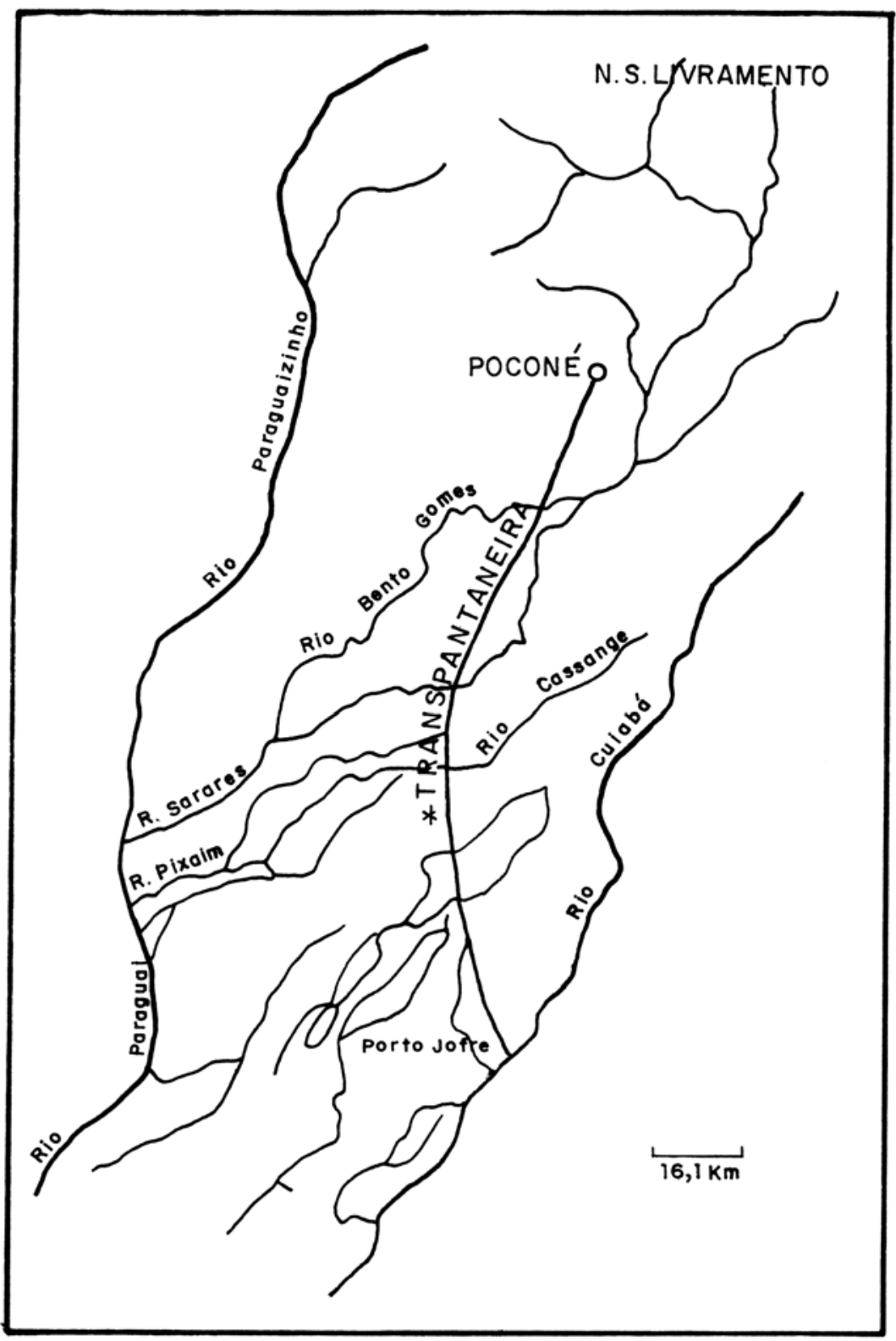

Figura 2 - Mapa do pantanal de Poconé com a localização da área de estudo.* 

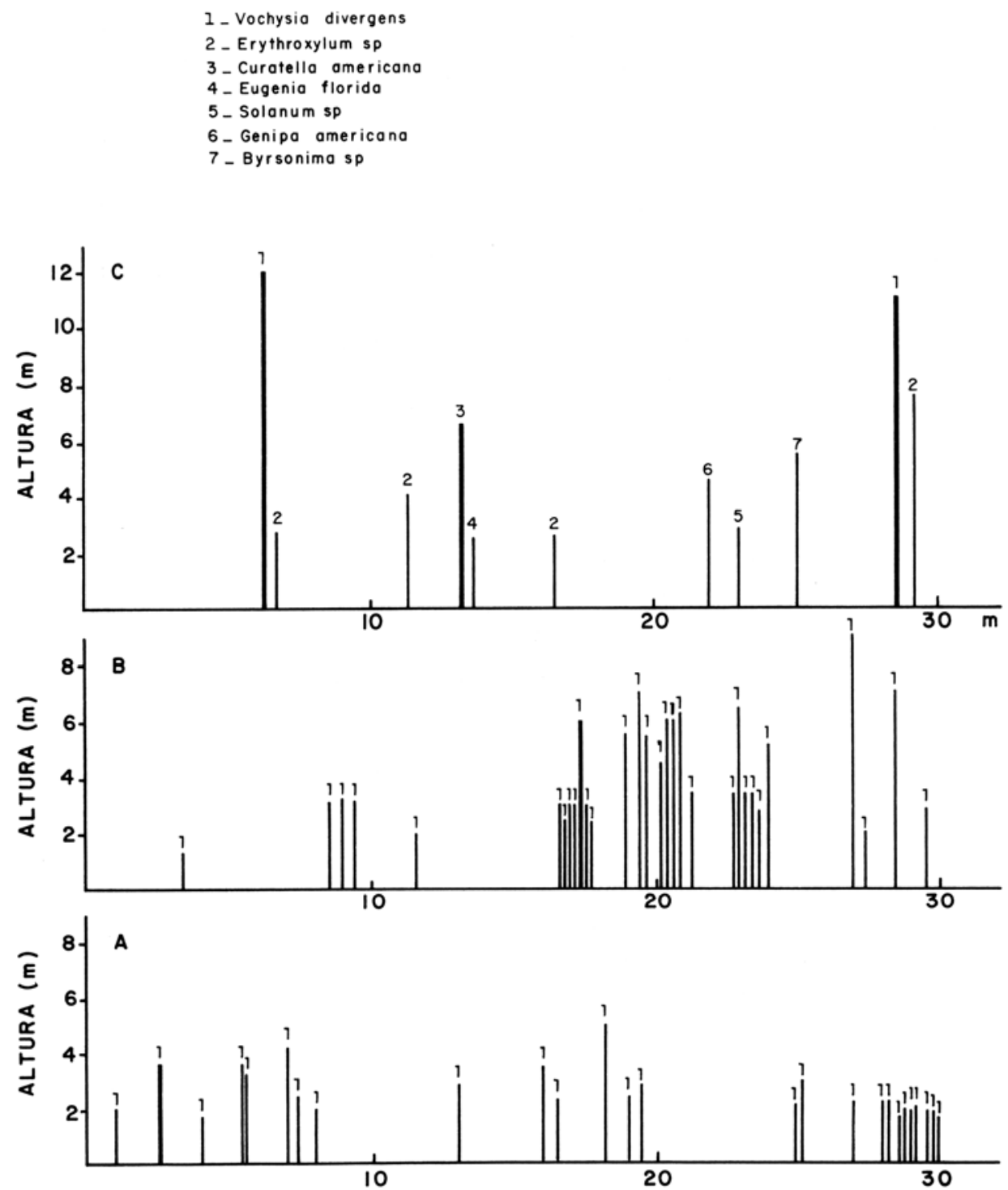

Figura 3 - Perfil simplificado da distribuição das árvores com CAS $\geqslant 10 \mathrm{~cm}$ (barra estreita) e com DAP $\geqslant 10 \mathrm{~cm}$ (barra grossa) em uma transecção linear de $1 \mathrm{~m} \mathrm{x}$ $30 \mathrm{~m}$. A $=$ transecção $1, \mathrm{~B}=$ transecção $2, \mathrm{C}=$ transecção 3 . 


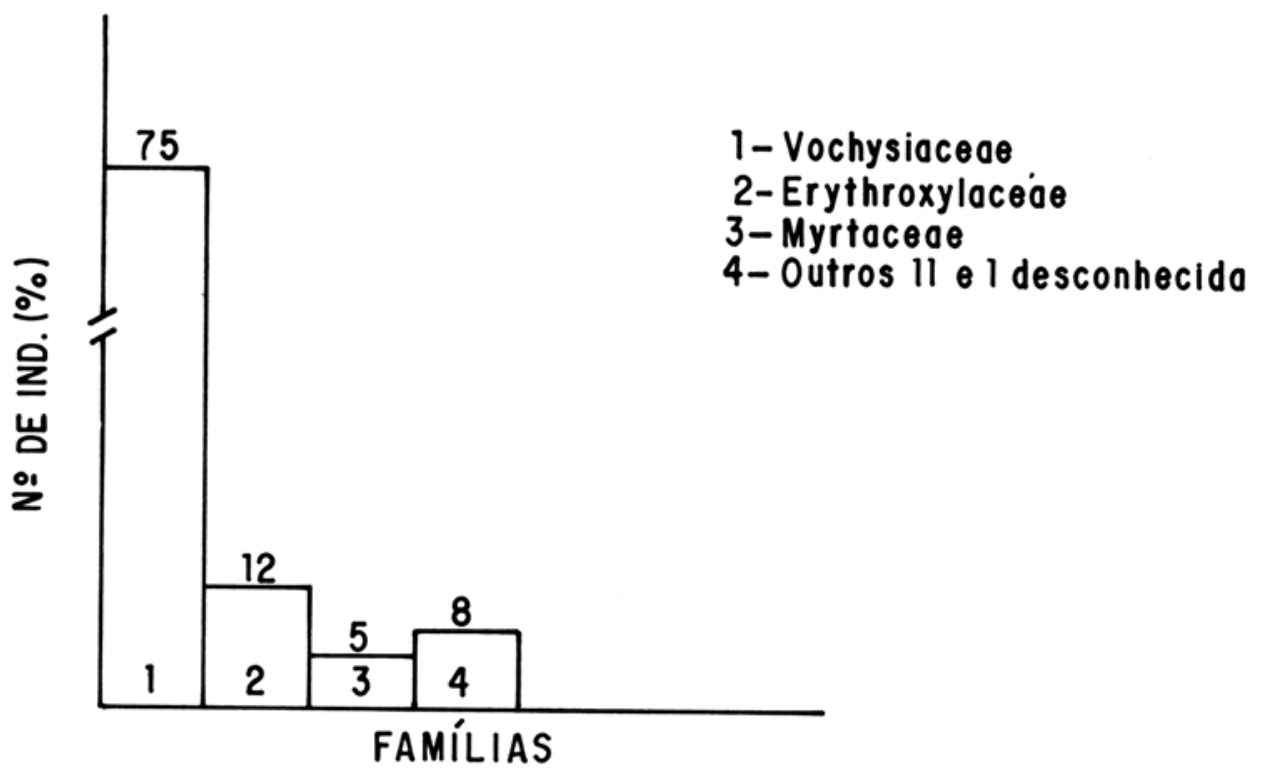

Figura 4 - Distribuição do número de indivíduos encontrados por família. 


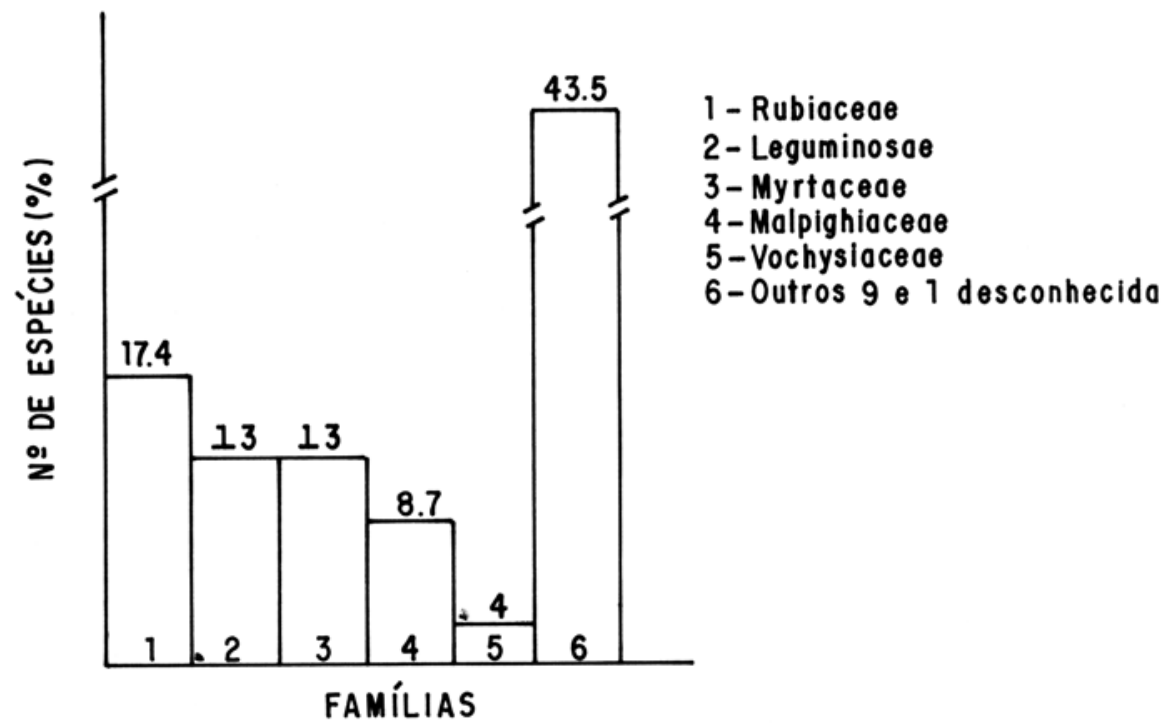

Figura 5 - Distribuição do número de espécies por família. 


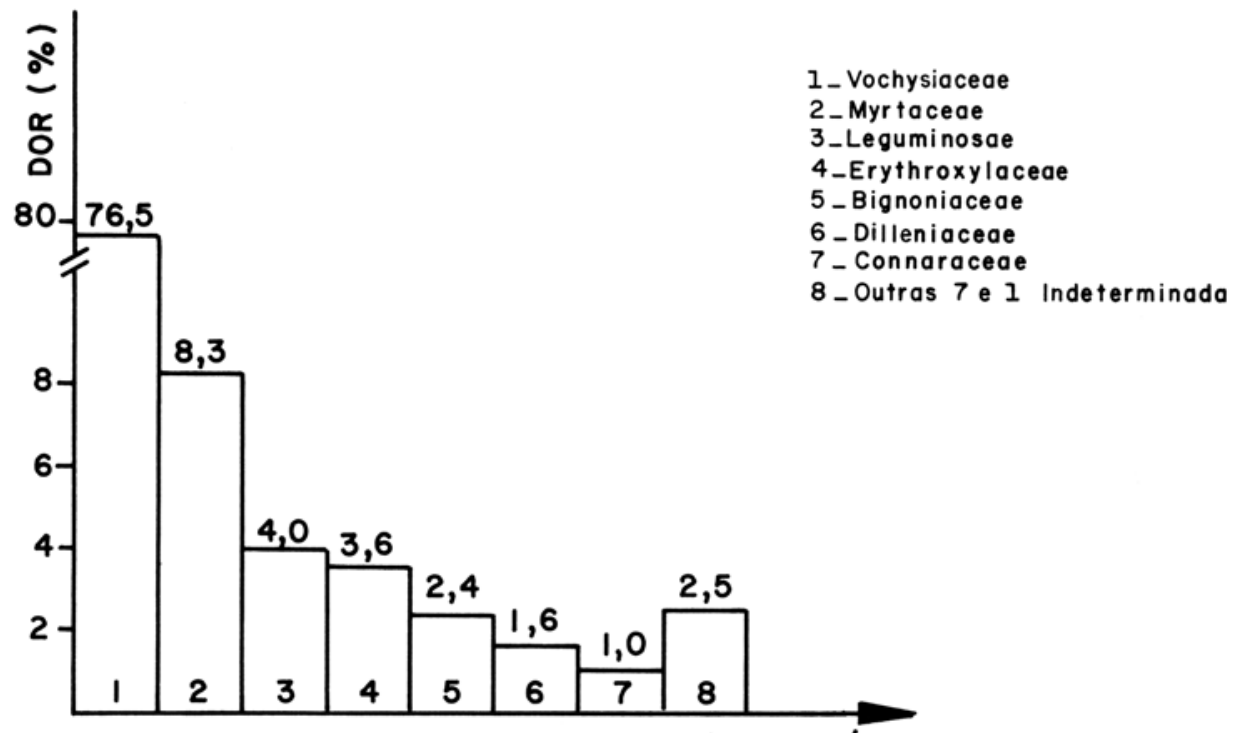

FAMÍLIA

Figura 6 - Distribuição da dominância relativa por família.

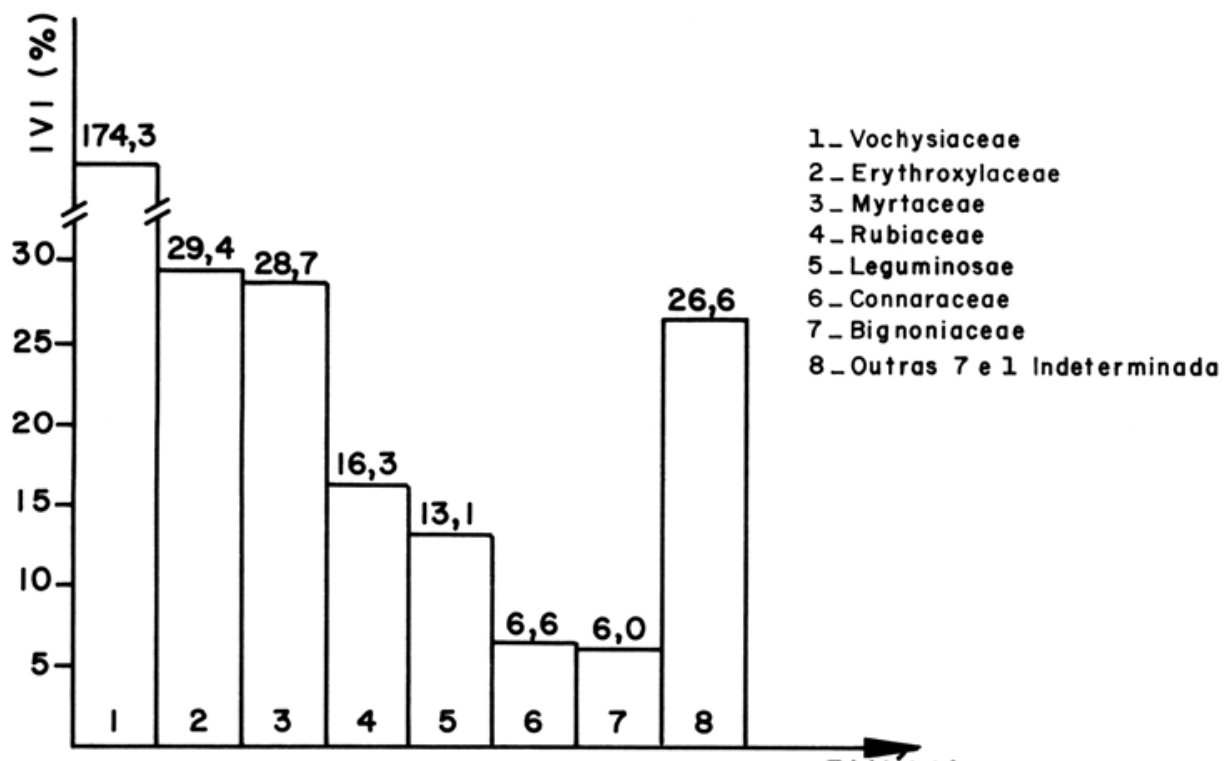

FAMÍLIA

Figura 7 - Distribuição do IVI por família. 


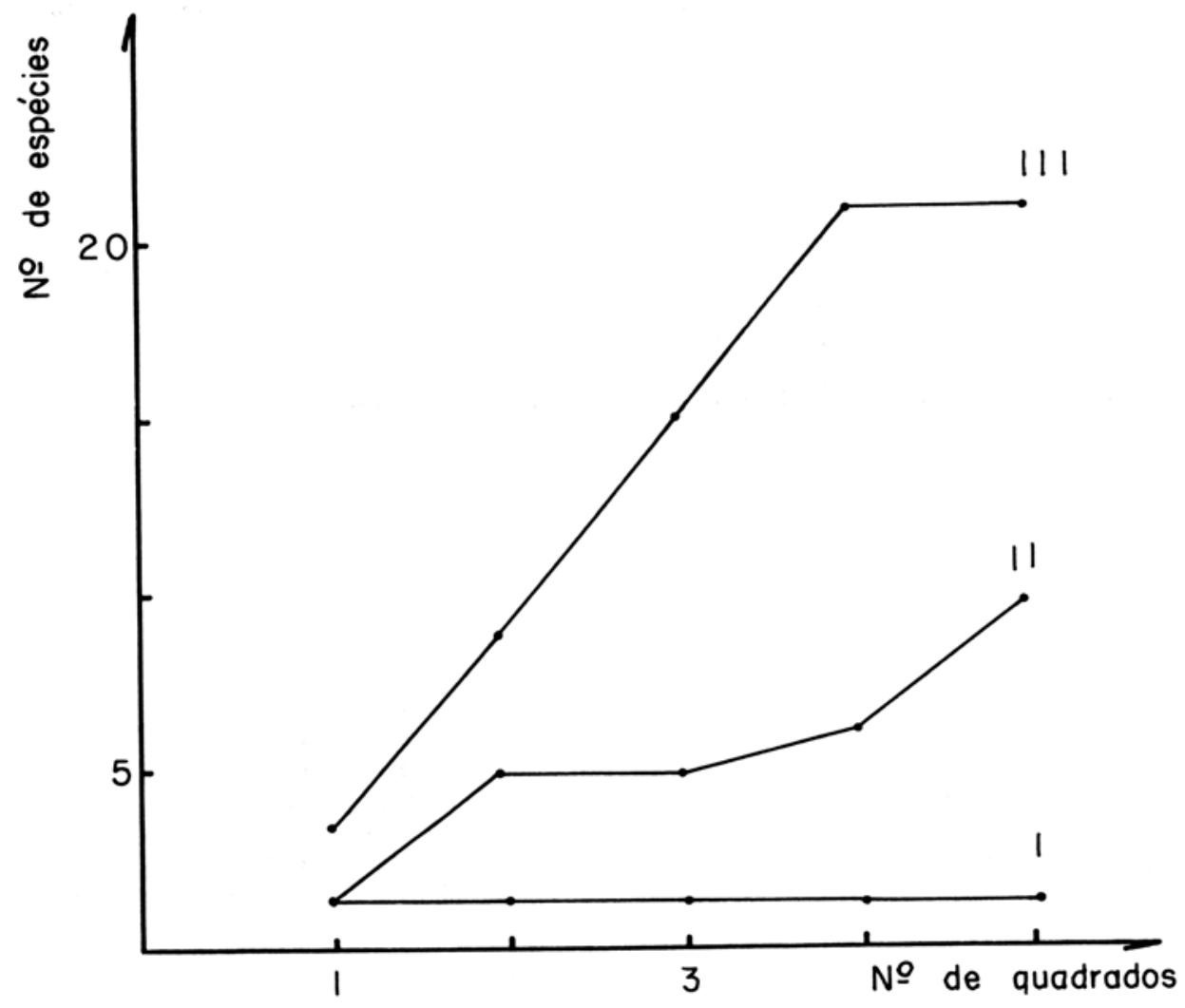

Figura 8 - Curvas de espécies/áreas das três transecçōes amostradas. 


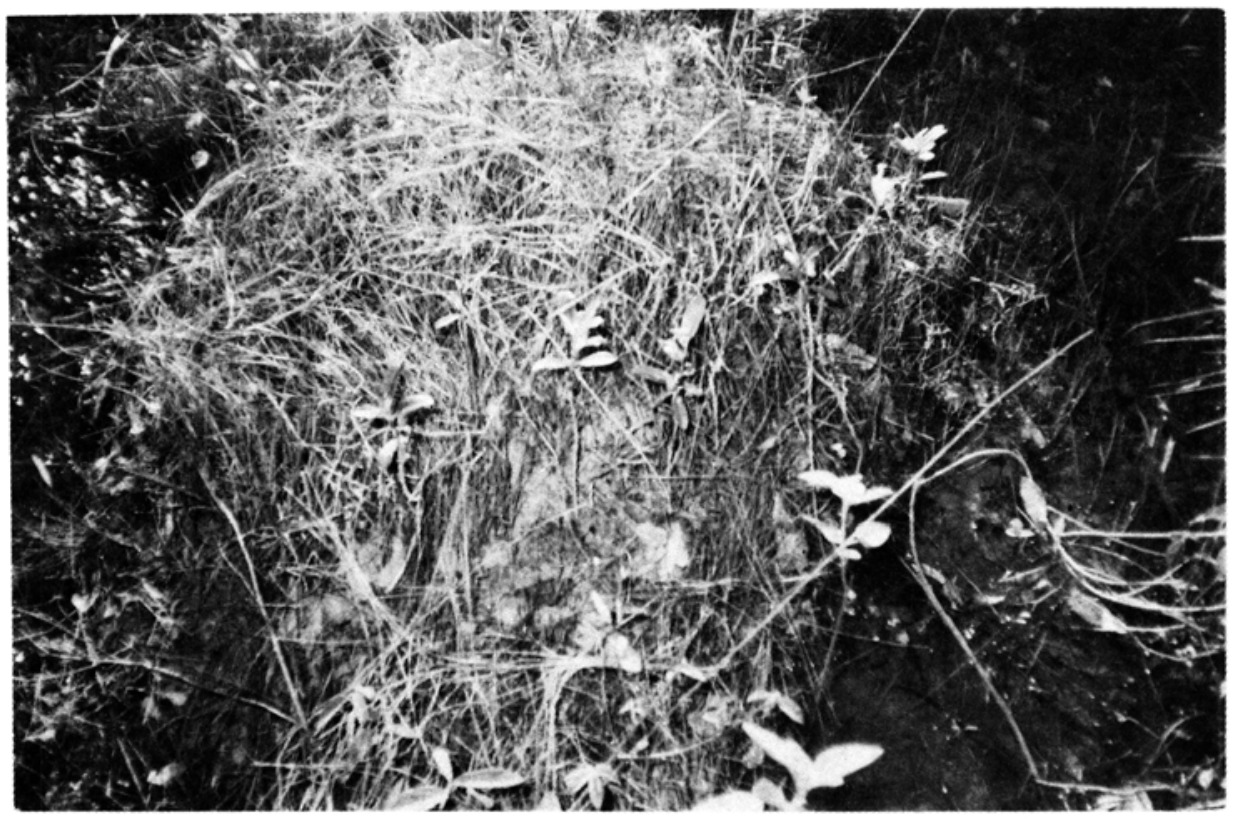

Figura 9 - Indivíduos jovens de $V$. divergens e de outras espécies que se estabeleceram em um murundum. 


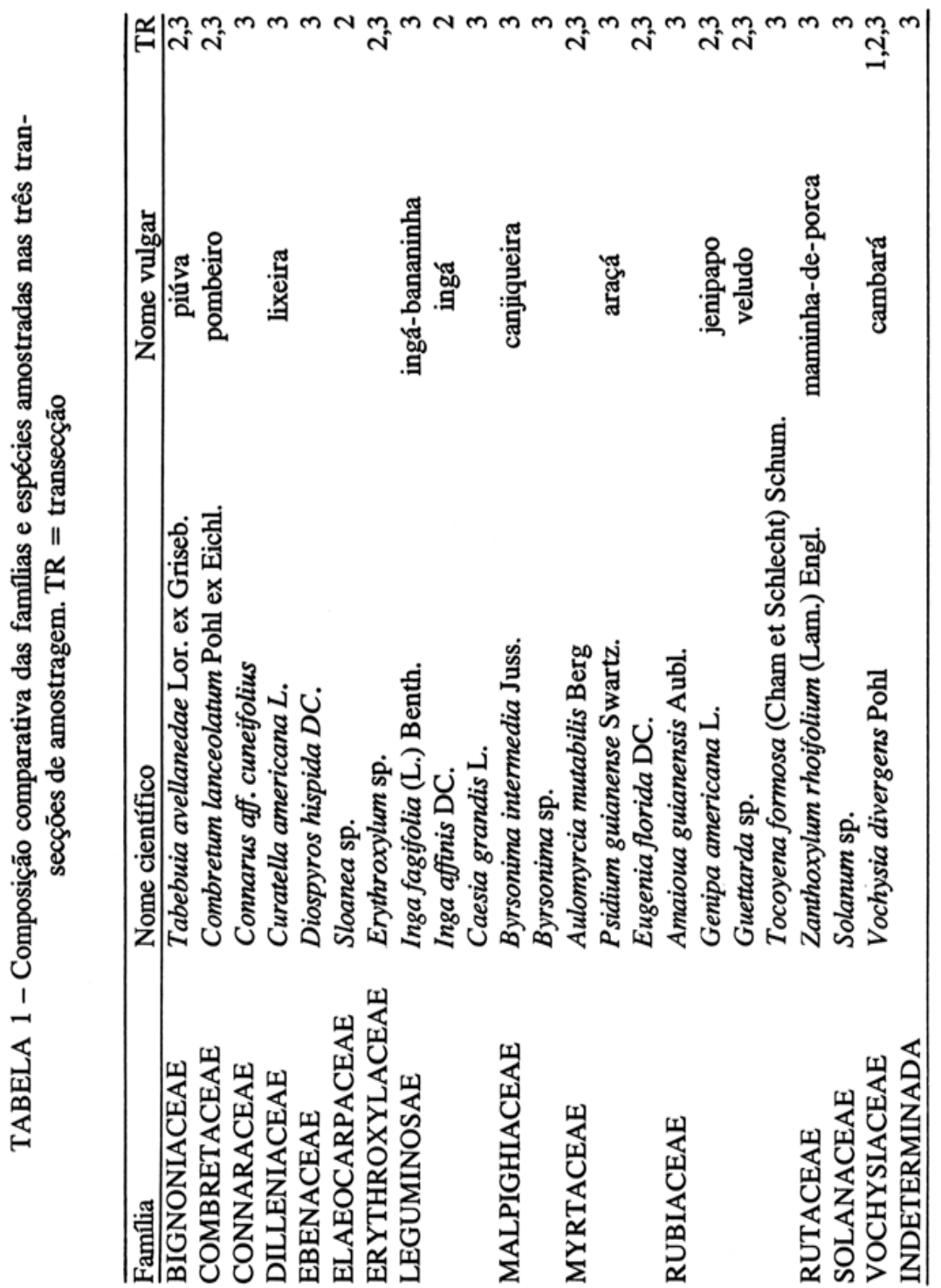


TABELA 2 - Espécies da transecção 2 e seus parâmetros fitossociológicos. CAS = circunferência à altura do solo $(\mathrm{cm}) ; \mathrm{A}=$ altura $(\mathrm{m}) ; \mathrm{ni}=$ número de indivíduos; $\mathrm{FR}=$ freqüência relativa; $\mathrm{DR}=$ densidade relativa; $\mathrm{DoR}=$ dominância relaiva e $\mathrm{IVI}=$ índice de valor de importânca

\begin{tabular}{lcrrrrrr}
\hline Nome científico & CAS & $\mathrm{A}$ & $\mathrm{ni}$ & $\mathrm{FR}$ & $\mathrm{DR}$ & DoR & IVI \\
\hline Vochysia divergens & 29 & 4,5 & 191 & 25 & 82,6 & 85,7 & 193,3 \\
Erythroxylum sp. & 15 & 3,5 & 22 & 20 & 9,6 & 1,7 & 31,3 \\
Inga affinis & 53 & 6,0 & 7 & 10 & 3,0 & 8,6 & 21,7 \\
Sloanea sp. & 25 & 6,0 & 3 & 10 & 1,3 & 0,5 & 11,8 \\
Guettarda sp. & 17 & 8,0 & 2 & 10 & 0,9 & 0,2 & 11,1 \\
Tabebuia avellanedae & 90 & 10,0 & 1 & 5 & 0,4 & 2,3 & 7,7 \\
Combretum lanceolatum & 38 & 3,5 & 1 & 5 & 0,4 & 0,4 & 5,8 \\
Eugenia florida & 24 & 6,0 & 1 & 5 & 0,4 & 0,2 & 5,6 \\
Aulomyrcia mutabilis & 23 & 5,0 & 1 & 5 & 0,4 & 0,1 & 5,5 \\
Genipa americana & 21 & 4,0 & 1 & 5 & 0,4 & 0,1 & 5,5 \\
TOTAL & - & - & 230 & 100 & 99,4 & 99,8 & 299,3 \\
\hline
\end{tabular}


TABELA 3 - Espécies da transeç̧ão 3 e seus parâmetros fitossociológicos. CAS = circunferência à altura do solo $(\mathrm{cm}) ; \mathrm{A}=$ altura $(\mathrm{m}) ; \mathrm{ni}=$ número de indivíduos; $\mathrm{FR}$ $=$ freqüência relativa; $\mathrm{DR}=$ densidade relativa; $\mathrm{DoR}=$ dominância relativa e IVI $=$ índice de valor de importância.

\begin{tabular}{lcrrrrrr}
\hline Nome científico & CAS & $\mathrm{A}$ & $\mathrm{ni}$ & $\mathrm{FR}$ & $\mathrm{DR}$ & DoR & IVI \\
\hline Vochysia divergens & 66 & 6,0 & 19 & 12,5 & 13,7 & 53,9 & 80,1 \\
Erythroxylum sp. & 19 & 4,0 & 54 & 12,5 & 38,8 & 7,6 & 58,9 \\
Aulomyrcia mutabilis & 38 & 4,0 & 20 & 10,0 & 14,9 & 20,8 & 45,7 \\
Connarus aff. cuneifolius & 35 & 4,5 & 6 & 7,5 & 4,6 & 2,8 & 14,9 \\
Solanum sp. & 31 & 3,5 & 8 & 5,0 & 5,7 & 0,9 & 11,6 \\
Curatella americana & 64 & 5,0 & 2 & 5,0 & 1,4 & 4,2 & 10,6 \\
Psidium aff. guianense & 14 & 4,0 & 6 & 5,0 & 4,3 & 0,4 & 9,7 \\
Eugenia florida & 21 & 3,0 & 4 & 5,0 & 2,9 & 0,6 & 8,5 \\
Tocoyena formosa & 18 & 2,5 & 4 & 5,0 & 2,9 & 0,2 & 8,1 \\
Inga fagifolia & 31 & 4,5 & 2 & 5,0 & 1,4 & 0,7 & 7,1 \\
Tabebuia avellanedae & 67 & 8,0 & 2 & 2,5 & 1,4 & 3,7 & 7,6 \\
Zanthoxylum rhoifoliom & 62 & 5,5 & 1 & 2,5 & 0,7 & 1,3 & 4,5 \\
Genipa americana & 26 & 4,5 & 2 & 2,5 & 1,4 & 0,5 & 4,4 \\
Byrsonima intermedia & 54 & 3,5 & 1 & 2,5 & 0,7 & 1,0 & 4,2 \\
Guettarda sp. & 19 & 5,0 & 2 & 2,5 & 1,4 & 0,2 & 4,1 \\
Combretum lanceolatum & 22 & 2,0 & 1 & 2,5 & 0,7 & 0,5 & 3,7 \\
Byrsonima sp. & 25 & 5,5 & 1 & 2,5 & 0,7 & 0,2 & 3,4 \\
Amaioua guianensis & 19 & 3,0 & 1 & 2,5 & 0,7 & 0,1 & 3,3 \\
Diospyros hispida & 16 & 3,5 & 1 & 2,5 & 0,7 & 0,1 & 3,3 \\
Caesia grandis & 12 & 4,0 & 1 & 2,5 & 0,7 & 0,1 & 3,3 \\
TOTAL & - & - & 139 & 97,5 & 99,7 & 99,8 & 297,0 \\
\hline
\end{tabular}


TABELA 4 - Comparação da estrutura do cambarazal com a de outros tipos vegetacionais. Incluída nos cálculos somente árvores com DAP $\varangle 10 \mathrm{~cm}$

\begin{tabular}{lllllll}
\hline Vegetação & H' & \multicolumn{6}{c}{ DT } & \multicolumn{3}{c}{ DAP Altura S } & Autor \\
& & & ind/ha $(\mathrm{cm})$ & $(\mathrm{m})$ & $(\mathrm{n})$ & \\
\hline cambarazal & 1,56 & 420 & 84 & 13 & 23 & Este estudo \\
mata atlântica & 4,07 & 816 & - & 35 & 123 & SILVA \& LEITÃo \\
& & & & & & FILHO (1982) \\
mata amazônica & - & 769 & 115 & 35 & 51 & TAKEUCHI (1960a) \\
& 3,83 & 423 & - & - & 87 & BLACK et al $(1950)$ \\
mata do igapó* & 4,36 & $5711-$ & 7 & 54 & KEEL\& PRANCE (1979) \\
& 3,55 & 564 & - & - & 60 & BLACK et al $(1950)$ \\
campina amazônica & - & - & 40 & 17 & 25 & TAKEUCHI (1960b) \\
manguezal & - & 800 & - & 10 & 2 & POOL et al. (1977) \\
\hline
\end{tabular}

* indivíduos $\geqq 1 \mathrm{~m}$ de altura 